\title{
Otology
}

\section{Management of cochlear fistula and the role of hearing: a five-case report}

\author{
Gestione della fistola cocleare e il ruolo dell'udito: report di 5 casi \\ Maurizio Falcioni ${ }^{1}$, Marco Govoni², Enrico Pasanisi², Filippo Di Lella² \\ ${ }^{1}$ Unit of Otorhinolaryngology and Otoneurosurgery, University Hospital of Parma, AOU Parma, Parma, Italy; ${ }^{2}$ Unit of \\ Otorhinolaryngology and Otoneurosurgery, University of Parma, Department of Medicine and Surgery, Parma, Italy
}

\begin{abstract}
SUMMARY
Objective. Cochlear fistula (CF) is a rare finding, usually associated with extensive middle ear cholesteatoma. There is agreement on the fact that removing the cholesteatoma matrix on a $\mathrm{CF}$ exposes the ear to a high risk of sensorineural hearing loss or dead ear. The aim of the study is to describe the presentation, possible treatment strategies and related outcomes for patients with $\mathrm{CF}$ in chronic otitis media (COM).

Methods. The study considers a retrospective case series of patients with CF diagnosis supported by CT-scan and intraoperative/otoscopic evidence.

Results. Five cases of CF were identified, 4 associated with cholesteatoma and 1 associated with non-cholesteatomatous COM. Two patients presenting with anacusis underwent a subtotal petrosectomy. Two patients with useful hearing underwent a radical mastoidectomy in order to preserve the cholesteatoma matrix on the promontorium. One patient with good hearing and COM was treated conservatively.

Conclusions. Conservative management should be considered for rare cases of CF in COM with residual hearing. Matrix preservation through radical/modified radical mastoidectomy is strongly advised in the presence of useful preoperative bone conduction. Subtotal petrosectomy should be considered the preferred option in presence of cholesteatoma with preoperative profound hearing loss.
\end{abstract}

KEY WORDS: cochlear fistula, promontory fistula, otitis media, cholesteatoma

\section{RIASSUNTO}

Obiettivo. La fistola cocleare $(F C)$ è una rara entità, solitamente associata a colesteatoma dell'orecchio medio. Vi è generale accordo in letteratura sul fatto che la rimozione della matrice colesteatomatosa da una FC determini elevato rischio di ipoacusia neurosensoriale o anacusia. Obiettivo dello studio è descrivere manifestazioni, possibili trattamenti e prognosi per pazienti affetti da FC.

Metodi. Serie retrospettiva di casi clinici di fistola cocleare confermati da TC e da riscontro intraoperatorio o endoscopico.

Risultati. Di 5 casi identificati, 4 si associavano a colesteatoma. Di questi, 2 pazienti anacusici venivano sottoposti a petrosectomia subtotale, mentre 2 pazienti udenti venivano sottoposti a intervento di radicale con preservazione della matrice sul promontorio. Il solo caso di FC associato a otite cronica non-colesteatomatosa (OMC) e con buon udito residuo veniva trattato conservativamente.

Conclusioni. Per quei rari casi di FC associati a OMC con buon udito residuo dovrebbe essere considerato un trattamento conservativo. In caso di via ossea preoperatoria protesizzabile, è fortemente indicata la preservazione della matrice di colesteatoma mediante mastoidectomia radicale o radicale modificata. In presenza di colesteatoma con perdita uditiva profonda pre-operatoria, una petrosectomia subtotale dovrebbe essere il trattamento di scelta.

PAROLE CHIAVE: fistola cocleare, fistola promontoriale, otite media, colesteatoma
Received: November 11, 2020

Accepted: July 23, 2021

Correspondence

Marco Govoni

Department of Otorhinolaryngology and Otoneurosurgery, University Hospital of Parma, via Gramsci 14, 43126 Parma, Italy

E-mail: marco.govoni90@gmail.com

Funding

None.

Conflict of interest

The Authors declare no conflict of interest.

How to cite this article: Falcioni M, Govoni M, Pasanisi E, et al. Management of cochlear fistula and the role of hearing: a five-case report. Acta Otorhinolaryngol Ital 2021;41:558-565. https:// doi.org/10.14639/0392-100X-N1237

() Società Italiana di Otorinolaringoiatria e Chirurgia Cervico-Facciale

\section{(c) (1) $)$}

This is an open access article distributed in accordance with the CC-BY-NC-ND (Creative Commons Attribution-NonCommercial-NoDerivatives 4.0 International) license. The article can be used by giving appropriate credit and mentioning the license, but only for non-commercial purposes and only in the original version. For further information: https:// creativecommons.org/licenses/by-nc-nd/4.0/deed.en 


\section{Introduction}

Labyrinthine fistula is one of the most common complications of cholesteatomatous-COM. It consists in a defect of the bony labyrinth, resulting in a direct contact between the cholesteatoma matrix and the labyrinthine endosteum or the membranous labyrinth ${ }^{1,2}$. The entire labyrinth can potentially be involved with the lateral semicircular canal as the most frequent site ${ }^{3}$. Cochlear involvement is a rare finding and cochlear fistula (CF) is usually associated with extensive middle ear cholesteatoma; association with noncholesteatomatous-COM is an even rarer entity ${ }^{4-6}$. For this reason, there are only few papers (excluding single case reports) focusing exclusively on $\mathrm{CF}^{7,8}$.

Preoperative clinical diagnosis of $\mathrm{CF}$ may be difficult as there are no specific audiological or otologic signs and symptoms ${ }^{4}$. Severe or profound sensorineural hearing loss (SNHL) is a frequent finding, but hearing examination can show a normal bony threshold as well. High resolution CT scan (HRCT) is a reliable imaging procedure for diagnosis of $\mathrm{CF}$, which typically appears as an erosion of the dense bone of the promontory ${ }^{3,6}$. An unrecognised CF represents a challenging situation during surgery, as inadvertent manipulation of the fistula is commonly associated with profound sensorineural hearing loss or dead ear ${ }^{1}$. Factors considered in therapeutic planning of a CF management usually include preoperative hearing status and disease extension (as documented by imaging) ${ }^{9}$. We report our experiences on a series of CFs with the purpose of discussing clinical aspects, surgical or conservative treatments and evaluating the results of long-term management.

\section{Materials and methods}

A retrospective chart review of patients treated by the authors between January 2005 and December 2017 was performed to examine clinical aspects and outcomes, of both surgical and conservative treatments, for patients affected by CF.

$\mathrm{CF}$ was defined as an opening in the cochlear bony labyrinth with exposure of the endosteal membrane; blue line cases were not included nor were patients affected by petrous bone cholesteatoma or other erosive skull base lesions. Only patients with a minimum follow-up of 12 months were enrolled. All available preoperative, postoperative and follow-up documentation (clinical history, otoscopic pictures, audiological evaluations, imaging studies and operative findings) were retrospectively reviewed. Pure-tone average of air conduction (AC-PTA) was calculated by averaging airconduction thresholds at $0.5,1,2$ and $4 \mathrm{kHz}$. The same values were considered for calculating the pure-tone average of bone-conduction (BC-PTA).

This study did not need any approval by the local Institu- tional Review Board, as specifically indicated (version 3, 03-07-2019). All procedures performed in this study involving human participants were in accordance with the 1964 Helsinki declaration and its later amendments or comparable ethical standards. No animals were involved.

\section{Results}

A total of 5 CFs were identified in 5 patients ( 3 females and 2 males, age range 27 to 85 years, mean age 60 years). Ipsilateral pure tone audiometry revealed pre-operative anacusis in 2 cases and mixed hearing loss in 3 cases. Four patients $(80 \%)$ referred vertigo or instability as presenting symptoms. In 3 cases instability was still present at the time of consultation. One patient (20\%) complained of tinnitus. Four patients (80\%) had a history of previous otologic surgery on the affected side. For each patient, a preoperative HRCT of the ear confirming the diagnosis was available. In 4 cases (80\%), imaging evaluation led to preoperative diagnosis of $\mathrm{CF}$, while in 1 case the fistula was detected during surgery. Four fistulae were located on the promontorial dome and 1 in continuity with the inferior border of the oval window.

Four patients were treated surgically and one was managed conservatively. The follow-up period ranged from 17 months to 15 years, with an average of 59 months. The 3 patients with measurable hearing at diagnosis did not show significant changes in the bony hearing threshold at the latest follow-up. No cholesteatoma recurrence was identified.

Details of clinical cases, treatment planning and surgical procedures are reported in the case discussions below. Two of the cases included in the present series (patient 3 and 4) have been reported in previous publications ${ }^{3,10}$.

\section{Case descriptions}

\section{Patient 1}

A 65-year-old female presented with complete deafness of the left ear, associated with recurrent otorrhoea, pain and mild vertigo for about 7 years. She referred a history of previous ipsilateral canal-wall-down tympanomastoidectomy (CWD) for cholesteatoma performed 36 years before. Audiogram showed left ear anacusis and right normoacusis. On otoscopy a recurrent cholesteatoma was present in the left sided cavity. CT-scan showed erosion of the promontorium with an area of ossification in the basal turn of the scala tympani (Fig. 1). MRI confirmed focal absence of fluid into the scala tympani. A subtotal petrosectomy (SP) was performed with complete cholesteatoma removal. Intraoperatively, the endosteum of the CF appeared preserved at the level of the 


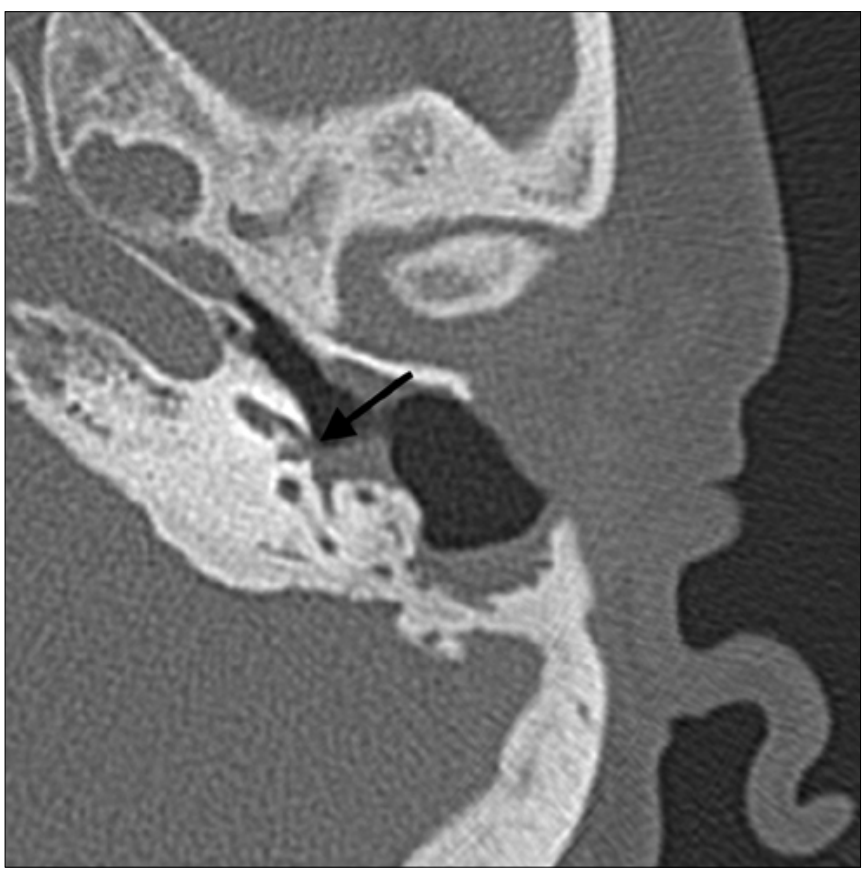

Figure 1. Patient 1. Temporal bone HRCT axial view (left ear): promontorial erosion with focal ossification of the scala tympani (arrow).

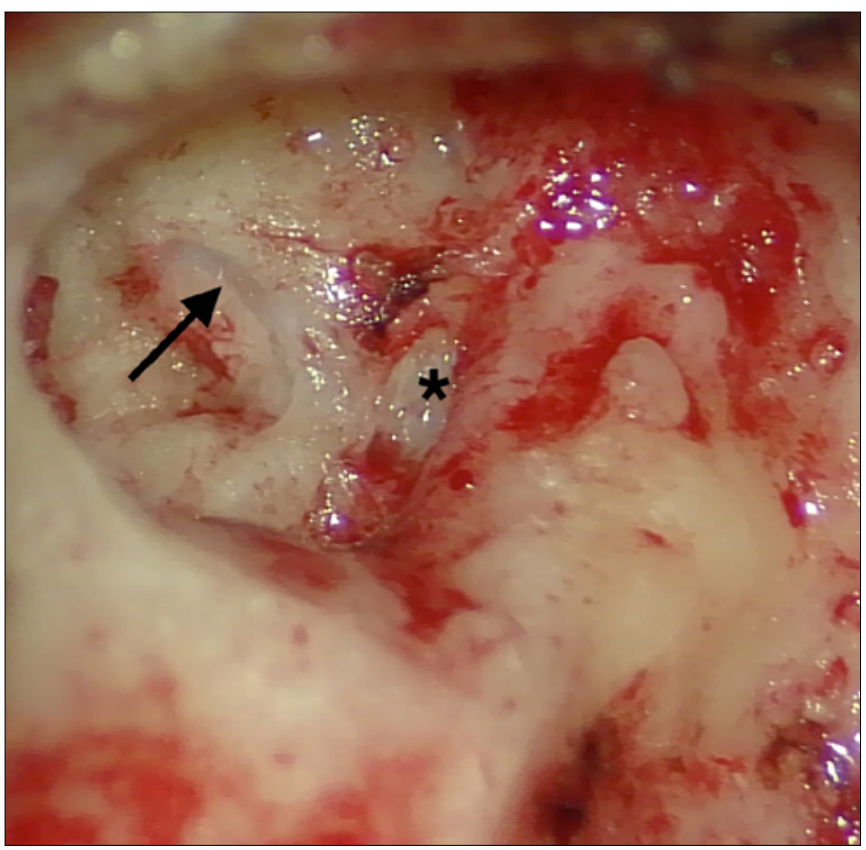

Figure 2. Patient 1. Subtotal petrosectomy of the left ear: exposed endosteum of the scala vestibuli is visible (arrow), ${ }^{*}$ footplate.

scala vestibuli (Fig. 2); a white area was visible in the scala tympani, corresponding to the radiologically identified ossification. At the 33-month follow-up, a diffusion weighted MRI did not show any disease recurrence.

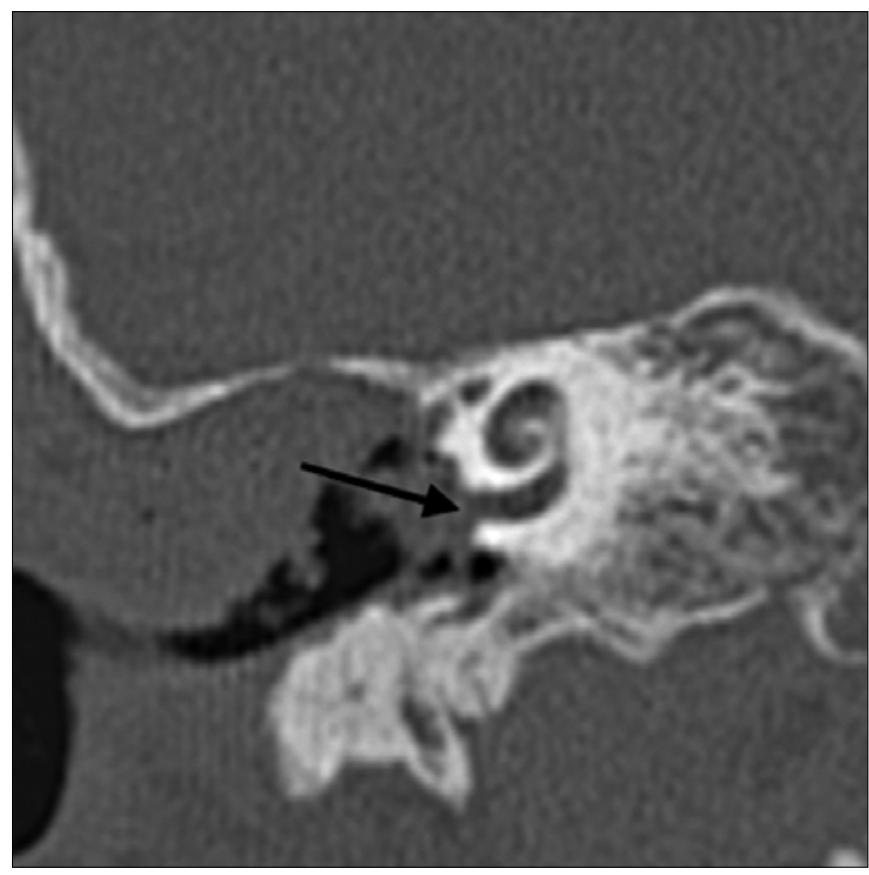

Figure 3. Patient 2. Temporal bone HRCT coronal view (right ear): an erosion of the promontory with a large fistula of the basal turn of the cochlea can be seen (arrow).

\section{Patient 2}

A 85-year-old female presented with worsening right sided hearing loss, which occurred after a week of violent vertigo and spontaneously resolved. She also reported a 10-year history of ipsilateral tinnitus and a previous ipsilateral radical mastoidectomy performed 34 years before.

Audiological evaluation showed a bilateral mixed hearing loss with AC-PTA $73 \mathrm{~dB}$ and BC-PTA $44 \mathrm{~dB}$ in the right ear. Otoscopy showed a right sided discharging radical cavity, absence of meatoplasty and trapped cholesteatoma, while CT-scan detected a CF (Fig. 3) as well as a large (i.e. $>2 \mathrm{~mm}$ ) fistula of the lateral semi-circular canal. The patient had a hearing aid fitted ipsilaterally, because an epitympanic/mesotympanic cholesteatoma was also present in the left ear, with a worse hearing condition (AC-PTA $93 \mathrm{~dB}$ and BC-PTA $55 \mathrm{~dB}$ ).

The patient underwent revision of the right radical mastoidectomy. In order to reduce the risk of hearing loss in the better hearing ear, the cholesteatoma matrix was preserved over both the fistula sites. Postoperative audiogram showed unchanged right hearing. After cavity healing, the patient was able to use her hearing aid. Seventeen months after surgery, there was no evidence of recurrence or worsening of hearing; the patient did not complain of dizziness/unsteadiness. She died for unrelated reasons at the age of 87 . 


\section{Patient 3}

A 47-year-old female presented with dizziness and right side otorrhoea. She also reported a history of right sided hearing loss occurred after ipsilateral tympanoplasty with mastoidectomy performed 18 years before. Otoscopy revealed lateralisation of the neotympanum with small posterior perforation and otorrhoea. Audiogram showed right hearing loss with AC-PTA $60 \mathrm{~dB}$ and BC-PTA $26 \mathrm{~dB}$. CTscan revealed total opacification of the right middle ear and mastoid with erosion of the tegmen tympani/mastoideum. The patient underwent surgical revision of the right ear tympanoplasty.

During surgery a large cholesteatoma was identified. Its initial removal from the middle ear cleft revealed an unusually enlarged oval window niche. With this premise, a second intraoperative analysis of CT-scan images revealed the presence of a $\mathrm{CF}$, which was undetected by the radiologist and surgeon during the preoperative evaluation. The surgical plan was then changed in favour of a radical cavity, leaving the matrix overlying the fistula in place. Postoperative audiogram showed hearing preservation with unchanged bony threshold. About 10 years later, the patient referred ipsilateral ear fullness associated with short vertigo spells and fluctuation of BC-PTA suggestive for hydrops. After corticosteroid therapy the symptoms subsided. At the last clinical control, 15 years after surgery, the patient did not present any disease recurrence, with the bony threshold showing $16 \mathrm{~dB}$ deterioration (BC-PTA $42 \mathrm{~dB}$ ). The contralateral BC-PTA remained unchanged.

\section{Patient 4}

A 27-year-old male was referred from another centre after a mastoidectomy for an acute mastoiditis. He reported a history of obstruction of the right external auditory canal and progressive ipsilateral hearing loss since he was 10 years old. Otoscopy revealed a bony mass obstructing the right external auditory canal. Tonal threshold audiometry showed right deafness and left side normal hearing. In CT and MRI performed before the previous mastoidectomy, the external auditory canal, middle ear and mastoid cells were occupied by material with a soft tissue density. The promontorium was eroded with a CF highlighted by air bubbles in the cochlear lumen. MRI also showed enhancement of the vestibule and lateral semi-circular canal extending to the whole length of the internal auditory canal. New CT and MRI were carried out with findings coinciding with the previous examination, except for a complete ossification of the inner ear and reduction of the enhancement of the internal auditory canal. The patient underwent SP with complete removal of cholesteatoma secondary to a huge external auditory canal osteoma. The $\mathrm{CF}$, as well

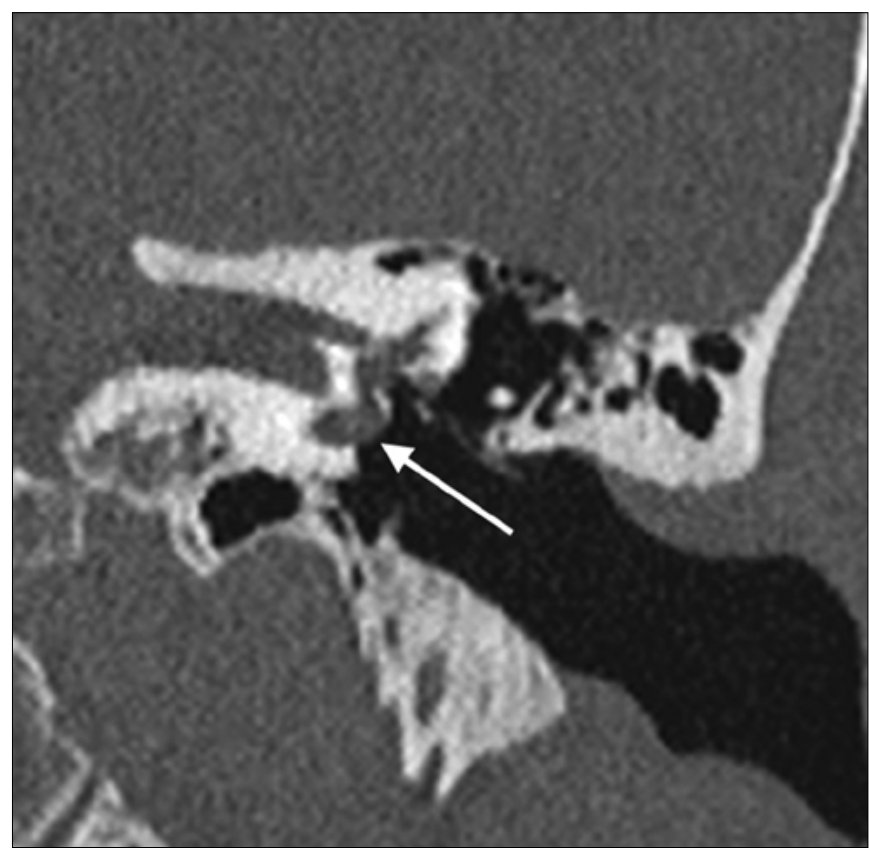

Figure 4. Patient 5. Temporal bone HRCT coronal view (left ear): a cochlear fistula can be seen on top of the promontory (arrow).

as the vestibule, appeared filled by fibrous and bony tissue. At the last control, 42 months after surgery, diffusion weighted MRI did not show any disease recurrence.

\section{Patient 5}

A 70-year-old male presented with bilateral hearing loss and dizziness. Left ear otoscopy showed posterior atelectasis. Audiological examination revealed a mixed hearing loss with BC-PTA $39 \mathrm{~dB}$ and AC-PTA $65 \mathrm{~dB}$. CT revealed a promontory erosion associated with the presence of a small mass with soft tissue density in the middle ear. Considering the good residual hearing, the patient underwent conservative treatment, based on otological and radiological follow-up. At the latest clinical control 24 months after diagnosis, a second CT did not show any significant change except for the disappearance of the small mass in the middle ear (Fig. 4). Hearing threshold was unchanged.

On micro-otoscopic and endoscopic evaluation, it was possible to visualise the fistula as a small circular dark area on the promontory, posterior to the umbus (Fig. 5). Patient data are detailed in Table I.

\section{Discussion}

Labyrinthine fistula is a common finding in cholesteatomatous chronic otitis, representing around $4-12 \%$ of its complications ${ }^{3,11}$. In a large meta-analysis, the lateral semicir- 
Table I. Patient data (continues on page 563).

\begin{tabular}{|c|c|c|c|c|c|c|c|c|}
\hline p. & $\begin{array}{c}\text { Age } \\
\text { (y) }\end{array}$ & Sex & $\begin{array}{l}\text { Previous } \\
\text { ME } \\
\text { surgery }\end{array}$ & $\begin{array}{l}\text { Presenting } \\
\text { symptoms }\end{array}$ & $\begin{array}{c}\text { Disease } \\
\text { duration (m) }\end{array}$ & Diagnosis & $\begin{array}{c}\mathrm{CF} \\
\text { stage * }\end{array}$ & $\begin{array}{c}\text { CF } \\
\text { Iocation }\end{array}$ \\
\hline 1 & 65 & $F$ & Yes & $\begin{array}{l}\text { Otorrhoea } \\
\text { pain } \\
\text { vertigo } \\
\text { deafness }\end{array}$ & 84 & Cholesteatoma & 1 & Promontory \\
\hline 2 & 85 & $F$ & Yes & $\begin{array}{c}\text { Vertigo } \\
\text { tinnitus } \\
\text { hearing loss }\end{array}$ & 120 & Cholesteatoma & $1 / 2$ & Promontory \\
\hline 3 & 47 & $\mathrm{~F}$ & Yes & $\begin{array}{l}\text { Otorrhoea } \\
\text { dizziness }\end{array}$ & 12 & Cholesteatoma & $1 / 2$ & OW border \\
\hline 4 & 27 & M & No & $\begin{array}{c}\text { Progressive hearing } \\
\text { loss }\end{array}$ & 204 & Cholesteatoma & 3 & Promontory \\
\hline 5 & 70 & M & No & $\begin{array}{c}\text { Dizziness } \\
\text { hearing loss }\end{array}$ & 6 & COM & $1 / 2$ & Promontory \\
\hline
\end{tabular}

ME: Middle Ear; CF: Cochlear Fistula; FU: follow-up; BC-PTA: pure-tone average of bone-conduction; LSC: Lateral Semicircular Canal; OW: Oval Window; COM: Chronic Otitis Media. ${ }^{*}$ According to Dornhoffer. In cases in which the matrix was not removed, it was impossible to precisely clarify the fistula.

cular canal was the most affected site with $87 \%$ of cases. Rarer locations include promontory (CF properly) with $8 \%$ of cases, superior semicircular canal with $6 \%$ of cases and posterior semicircular canal with $2 \%$ of cases ${ }^{11}$. Moreover, $\mathrm{CF}$ is frequently associated with otic capsule erosion in other areas of labyrinth ${ }^{12}$. This frequent association and the rarity of $\mathrm{CF}$ itself are the main reasons for a substantial lack of specific literature on $\mathrm{CF}$, with most of the articles

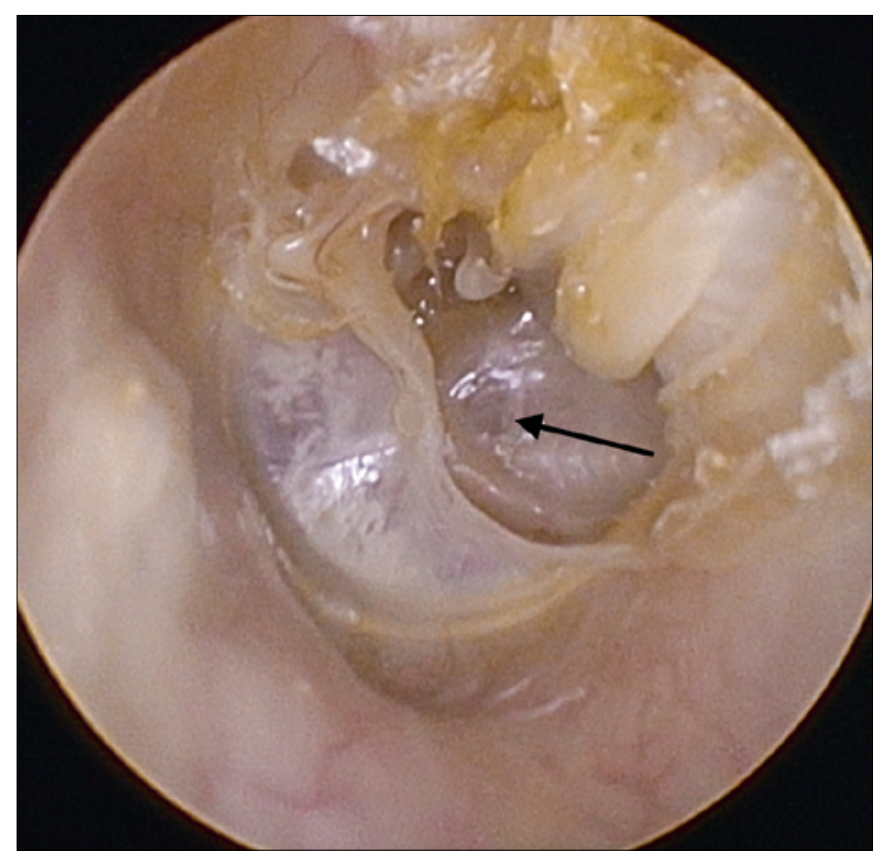

Figure 5. Patient 5. Otoendoscopy of the left ear: a dark area corresponding to the cochlear fistula (arrow) is visible through the atelectasis on the promontory, posterior to the umbus. and studies including labyrinthine and cochlear fistulae at the same time.

The literature only reports sporadic CF cases associated with non-cholesteatomatous chronic otitis media ${ }^{4-6}$. This trend was confirmed by our study with 4 of 5 cases of $\mathrm{CF}$ associated with cholesteatoma.

Cholesteatoma can generate a fistula through 3 different mechanisms: pressure exerted by the matrix, enzymatic osteolysis and inflammation ${ }^{7,13}$. Promontory is not a common area for perimatrix substances to accumulate and considering its position, it is subjected to very low physical pressure from overlying tissues ${ }^{6}$. All these factors can justify the rarity of CF.

Various classifications have been proposed for labyrinthine fistulae which can be adopted for cochlear ones as well. Palva and Johnnson ${ }^{14}$ in 1986 proposed a staging system based on severity of otic capsule destruction. The preliminary stage is the blue line: a bony erosion of the otic capsule without a real fistula. Stage 1 is defined by exposure of endosteal membrane, which remains intact. In stage 2, the cholesteatoma matrix is in contact with the perilymphatic space. In stage 3, the perilymphatic space is also open and the cholesteatoma involves the membranous labyrinth directly. The main problem of this classification is the impossibility to stage the fistula preoperatively relying on radiologic findings only. Sometimes, in case of matrix preservation when the fistula is not uncovered, it is not possible even postoperatively.

A more common classification of fistulae is by its size. Sanna et al. ${ }^{15}$ in 1986 defined 3 types of fistula based on dimensional criteria: small $(0.5-1 \mathrm{~mm})$, medium $(1-2 \mathrm{~mm})$ and large fistulae $(>2 \mathrm{~mm})$ as assessed by intraoperative 
Table I. Patient data (follows from page 562).

\begin{tabular}{|c|c|c|c|c|c|c|c|c|}
\hline p. & $\begin{array}{l}\text { Age } \\
\text { (y) }\end{array}$ & $\begin{array}{l}\text { Associated } \\
\text { labyrinthine } \\
\text { fistula }\end{array}$ & $\begin{array}{c}\text { CF } \\
\text { management }\end{array}$ & $\begin{array}{l}\text { Disease } \\
\text { recurrence }\end{array}$ & FU length (m) & $\begin{array}{c}\text { Pre-op } \\
\text { BC-PTA (dB) }\end{array}$ & $\begin{array}{c}\text { Post-op } \\
\text { BC-PTA (dB) }\end{array}$ & $\begin{array}{c}\text { Last FU } \\
\text { BC-PTA (dB) }\end{array}$ \\
\hline 1 & 65 & No & $\begin{array}{l}\text { Complete matrix } \\
\text { removal }\end{array}$ & No & 33 & Dead ear & Dead ear & Dead ear \\
\hline 2 & 85 & LSC & Matrix preservation & No & 17 & 44 & 44 & 46 \\
\hline 3 & 47 & No & Matrix preservation & No & 180 & 26 & 23 & 41 \\
\hline 4 & 27 & LSC & $\begin{array}{l}\text { Complete matrix } \\
\text { removal }\end{array}$ & No & 42 & Dead ear & Dead ear & Dead ear \\
\hline 5 & 70 & No & Follow-up & No & 24 & 39 & l & 39 \\
\hline
\end{tabular}

E: Middle Ear; CF: Cochlear Fistula; FU: follow-up; BC-PTA: pure-tone average of bone-conduction; LSC: Lateral Semicircular Canal; OW: Oval Window; COM: Chronic Otitis Media. ${ }^{*}$ According to Dornhoffer. In cases in which the matrix was not removed, it was impossible to precisely clarify the fistula.

visual measurements, with consistent possible biases. The two classifications may overlap as larger fistulae more frequently involve the inner ear structures ${ }^{16}$ which is the main reason for SNHL following surgical treatment. Dornhoffer ${ }^{17}$ in 1995 published a three-point classification system for labyrinthine fistulae, applied to cochlear ones as well, and based on the degree of the labyrinth involvement. Type I fistula was considered to be an erosion of the bony labyrinth with an intact endosteum. A true fistula with an opened perilymphatic space was defined as a Type II fistula. Finally, an opened perilymphatic space with involvement or destruction of the underlying membranous labyrinth was classified as a Type III fistula.

History of vertigo is reported in about $64 \%$ of patients affected by labyrinthine fistula and profound SNHL is found in $15 \%$ of cases ${ }^{11}$. Similar data referring specifically to CF are missing in the literature. In our series, a history of mild dizziness was reported by 3 of 5 patients $(60 \%)$ with only 1 patient $(20 \%)$ affected by severe vertigo, probably related to a complete amputation of lateral semi-circular canal (patient 2). In addition, 2 of 5 patients $(40 \%)$ had a dead ear at diagnosis. Radiological and intraoperative findings confirmed labyrinthitis as the reason for the dead ear. The other 3 cases showed a BCPTA at diagnosis similar to the contralateral one (even better in case 2). Therefore, CF may not always be accompanied by specific ear symptoms and a high index of suspicion is required in all cases of COM ${ }^{18}$.

It should be noted that in this series $80 \%$ of $\mathrm{CF}$ were diagnosed in previously operated ears. However, one of these surgeries did not include any access to the middle ear cleft (case 4); neither in the other 3, being the prom- ontory a site where the use of the drill is exceptional, a iatrogenic aetiology seems unlikely.

According to the literature, $\mathrm{CT}$ is a reliable diagnostic tool that is able to detect findings suggestive for labyrinthine fistula in up to $97 \%$ of cases 19,20 . Improvement in resolution of CT imaging during the last 20 years has led to possible preoperative identification in virtually all cases. CF is detectable in both axial and coronal planes, even if identification seems to be easier on coronal planes ${ }^{3,6}$. In our series, CF was visible in scans in all cases $(100 \%)$, even if the fistula located at the inferior border of the oval window was more difficult to identify. However, because of the extreme rarity of $\mathrm{CF}$, radiologists and surgeons may fail to detect it during routine imaging evaluation ${ }^{5}$. This occurred in 1 patient of our series, when the CF was detected in the scan only after its intraoperative re-evaluation, after a suspect enlargement of oval window was visualised during surgery. Kwon et al. ${ }^{5}$ also described a similar case in which a CF was suspected during a canal-wall-up tympanomastoidectomy (CWU) and confirmed by intraoperative review of CT images. In addition, it has to be considered that not all patients affected by chronic otitis media without cholesteatoma undergo CT before surgery. Redaelli de Zinis et al. ${ }^{6}$ in 2005 published a case of CF diagnosed during tympanoplasty for non-cholesteatomatous chronic otitis media that was confirmed only by post-operative CT.

As already reported, the majority of cases of $\mathrm{CF}$ present in association with cholesteatoma and require surgical treatment. However, the unusual occurrence of a CF in non-cholesteatomatous-COM may also be managed conservatively, as in our patient 5 . In similar cases, surgical alternatives can be removal of the matrix, with risk of a SNHL, or radi- 
cal/modified radical mastoidectomy, which could cause a worsening of conductive component of the preoperative hearing loss.

The surgical management of labyrinthine fistula has been a debated issue in literature, with some authors defending a more aggressive surgical approach (matrix removal) and others more conservative management (matrix preservation). When surgically addressing a CF, it must be kept in mind that the cochlear duct is adherent to the lateral wall of the cochlear lumen; erosion of the promontorial endosteum determines direct contact between the cholesteatoma matrix and cochlear duct, exposing the latter to a high risk of damage during any matrix manipulation. As a consequence, in the presence of a $\mathrm{CF}$ there is a general agreement that matrix removal entails a higher risk of profound sensorineural hearing loss/dead ear ${ }^{1,11,21}$. The reported cases of hearing preservation are probably mainly related to fistulae with preservation of the endosteal layer, an occurrence extremely difficult to predict from the CT scan. This makes the pre-operative hearing status the most important parameter to select the appropriate surgical option.

In our series, 2 of 5 patients (40\%) presented with anacusis of the affected ear. In these cases, therapeutic choice leaned in favour of a SP ${ }^{22}$ with complete excision of cholesteatoma, including the fistula matrix. In both cases, CFs were occupied by fibrotic tissue with foci of ossifications, as sequelae of previous labyrinthitis (well documented radiologically).

In presence of an already dead ear, SP with external auditory canal closure, Eustachian tube plugging and cavity obliteration reduces the chances of disease recurrence and cavity problems; if required, it can also be combined with a labyrinthectomy for patients reporting severe vertigo spells ${ }^{23}$. As a rule, SPs need to be periodically checked with MRI to exclude any residual cholesteatoma ${ }^{24}$.

Patients 2 and 3 presented with BC-PTA 44 and 26, respectively, on the affected ear. In both these cases, preservation of residual hearing was considered a priority and a matrix preservation strategy was selected. Preserving cholesteatoma matrix on the promontorium reduces the surgical options to a radical or modified radical mastoidectomy ${ }^{25}$, because the promontorium (at least the area covered by the matrix) must remain exteriorized ${ }^{21}$. The BC-PTA of patient 3 showed a $16 \mathrm{~dB}$ deterioration after 15 years of $\mathrm{FU}$, probably the consequence of some hydropic attacks occurred 10 years after the surgery.

An alternative treatment for labyrinthine fistula associated with cholesteatoma is removing the disease in a 2-stage procedure. This technique is usually performed on SCC fistulas ${ }^{15}$. However, there is not a specific report on CF.

It should also be stressed that all patients affected by labyrinthine fistula treated with matrix preservation are at risk for SNHL/anacusis consequent to a labyrinthitis, as reported by Palva et al. ${ }^{26}$ and also observed by the authors in 2 unpublished cases.

This series has some limitations. No definitive conclusions can be drawn from a series of 5 patients. In addition, classifications cannot be precisely applied to fistulas that are managed conservatively, because only matrix removal allows a clear visualisation of the actual cochlear involvement. Despite the limitations of this study, in the authors' opinion, management of CF should be based on imaging, intraoperative findings and pre-operative hearing status.

\section{Conclusions}

$\mathrm{CF}$ is a rare finding and even if $\mathrm{CT}$ is a reliable diagnostic tool for its identification, it may sometimes remain undetected because of its rarity.

Although no definitive conclusions can be drawn from a series of 5 patients, in the authors' opinion, management of CF should be based on imaging, intraoperative findings and, most of all, pre-operative hearing status. In the presence of a preoperative dead ear or severe to profound $\mathrm{SN}$ HL, a SP may be considered the first option. In cases with useful BC-PTA, hearing preservation should be the main purpose of treatment. Clinical and radiological follow-ups may be effective therapeutic choices for cases of CF related to non-cholesteatomatous $\mathrm{COM}$ with residual hearing. In the presence of cholesteatoma, matrix preservation is recommended by the authors through a radical/modified radical mastoidectomy, especially in the only or better hearing ear.

\section{References}

1 Gacek RR. The surgical management of labyrinthine fistulae in chronic otitis media with cholesteatoma. Ann Otol Rhinol Laryngol Suppl 1974;83:1-19. https://doi.org/10.1177/00034894740830S101

2 Yang JM, Chi FL, Han Z, et al. Clinical characteristics of patients with labyrinthine fistulae caused by middle ear cholesteatoma. Chin Med J (Engl) 2013;126:2116-2119. https://doi.org/10.3760/ cma.j.issn.0366-6999.20123026

3 Falcioni M, Lauda L. Cochlear fistula in recurrent cholesteatoma. Otol Neurotol 2006;27:284. https://doi.org/10.1097/01. mao.0000194817.92426.64

4 Hahn Y, Bojrab DI. Cochlear fistula in a noncholesteatomatous ear. Ear Nose Throat J 2014;93:E9-E10. https://doi. org/10.1177/014556131409300903

5 Kwon C, Choi JH, Woo HY. Cochlear fistula in chronic otitis media without cholesteatoma. J Audiol Otol 2017;21:112-114. https://doi. org/10.7874/jao.2017.21.2.112

6 Redaelli de Zinis LO, Campovecchi C, Gadola E, et al. Fistula of the cochlear labyrinth in noncholesteatomatous chronic otitis media. Otol Neurotol 2005;26:830-833. https://doi.org/10.1097/01. mao.0000169638.48193.b2 
7 Sunwoo W, Lee SY, Seong J, et al. Clinical characteristics of patients with cochlear fistulas caused by chronic otitis media with cholesteatoma. J Int Adv Otol 2020;16:40-46. https://doi.org/10.5152/ iao. 2020.7018

8 Kang WS, Song CI, Yoon TH. Cochlear implantations in patients with cochlear fistulae. Otolaryngol Head Neck Surg 2010;143:463-464. https://doi.org/10.1016/j.otohns.2010.04.023

9 Sagar P, Devaraja K, Kumar R, et al. Cholesteatoma induced labyrinthine fistula: is aggressiveness in removing disease justified? Indian J Otolaryngol Head Neck Surg 2017;69:204-209. https://doi. org/10.1007/s12070-017-1072-y

10 Iaccarino I, Bozzetti F, Piccioni LO, et al. A case of external auditory canal osteoma complicated with cholesteatoma, mastoiditis, labyrinthitis and internal auditory canal pachymeningitis. Acta Otorhinolaryngol Ital 2019;39:358-362. https://doi.org/10.14639/0392-100X-1547

11 Copeland BJ, Buchman CA. Management of labyrinthine fistulae in chronic ear surgery. Am J Otolaryngol 2003;24:51-60. https://doi. org/10.1053/ajot.2003.10

12 Gamoletti R, Sanna M, Zini C. Inner ear cholesteatoma and the preservation of cochlear function. J Laryngol Otol 1990;104:945-948. https://doi.org/10.1017/s0022215100114446

13 Hamzei M, Ventriglia G, Hagnia $M$, et al. Osteoclast stimulating and differentiating factors in human cholesteatoma. Laryngoscope 2003;113:436-442. https://doi. org/10.1097/00005537-200303000-00009

14 Palva T, Johnsson LG. Preservation of hearing after removal of the membranous canal with a cholesteatoma. Arch Otolaryngol Head Neck Surg 1986;112:982-985. https://doi.org/10.1001/ archotol.1986.03780090078015

15 Sanna M, Zini C, Gamoletti R, et al. Closed versus open technique in the management of labyrinthine fistulae. Am J Otol 1988;9:470-475.

16 Jang $\mathrm{CH}$, Merchant SN. Histopathology of labyrinthine fistulae in chronic otitis media with clinical implications. Am J Otol 1997; 18:15-25.
17 Dornhoffer JL, Milewski C. Management of the open labyrinth. Otolaryngol Head Neck Surg 1995;112:410-414. https://doi.org/10.1016/ s0194-5998(95)70275-x

18 Priyanka M, Anjali L, Ramanathan C, et al. Labyrinthine fistulae in squamosal type of chronic otitis media: therapeutic outcome. Iran J Otorhinolaryngol 2019;31:167-172.

19 Fuse T, Tada Y, Aoyagi M, et al. CT detection of facial canal dehiscence and semicircular canal fistula: comparison with surgical findings. J Comput Assist Tomog 1996;20:221-224. https://doi. org/10.1097/00004728-199603000-00009

20 Meyer A, Bouchetemblé P, Costentin B, et al. Lateral semicircular canal fistula in cholesteatoma: diagnosis and management. Eur Arch Otorhinolaryngol 2016;273:2055-2063. https://doi.org/10.1007/ s00405-015-3775-6

21 Lim J, Gangal A, Gluth MB. Surgery for cholesteatomatous labyrinthine fistula. Ann Otol Rhinol Laryngol 2017;126:205-215. https:// doi.org/10.1177/0003489416683193

22 Prasad SC, Roustan V, Piras G, et al. Subtotal petrosectomy: surgical technique, indications, outcomes, and comprehensive review of literature. Laryngoscope 2017;127:2833-2842. https://doi.org/10.1002/ lary. 26533

23 Sykopetrites V, Giannuzzi AL, Lauda L, et al. Surgical labyrinthectomy and cochlear implantation in Menière's disease. Otol Neurotol 2020;41:775-781. https://doi.org/10.1097/MAO.0000000000002646

24 Delrue S, De Foer B, van Dinther J, et al. The value of diffusionweighted MRI in the long-term follow-up after subtotal petrosectomy for extensive cholesteatoma and chronic suppurative otitis media. Otol Neurotol 2019;40:E25-E31. https://doi.org/10.1097/ MAO.0000000000002049

25 Sanna M, Sunose H, Mancini F, et al. Canal Wall Down (Open) timpanoplasty. In: Sanna M, Sunose H, Mancini F, Russo A, Taibah A, Falcioni M, editors. Middle ear and mastoid microsurgery. Second edition. New York: Thieme 2012

26 Palva T, Kärjä J, Palva A. Opening of the labyrinth during chronic ear surgery. Arch Otolaryngol 1971;93:75-78. https://doi.org/10.1001/ archotol.1971.00770060107014 